\title{
Social Accountability: Medical Education's Boldest Challenge
}

\section{By Charles Boelen, MD, MPH, MSc}

In this century, medical schools will be gauged by their capacity to anticipate the kind of doctors required by evolving health systems. They will need to consider the challenges these health systems face as they grapple with critical health concerns in society. In this context, two things immediately become apparent: one, the roots of ill health lie in poverty, discrimination, lack of education, maldistribution and misuse of often scarce resources; and two, in any given country, those who identify health issues, act on health determinants, decide on the use of resources, deliver health services, or train health manpower are usually different groups that may not share the same value system and priorities. Thus, fragmentation is a serious threat to the efficiency and effectiveness of health systems everywhere.

These observations set the table for some tough questions: What readjustments do health systems need to make? What roles should doctors play? Which responsibilities should medical schools shoulder to contribute to the development of healthier societies? I like to think that being aware of these overarching issues is a first step towards social accountability.

Social accountability of medical schools is defined by the World Health Organization (WHO) as "the obligation to direct their education, research and service activities towards addressing the priority health concerns of the community, the region, and/or the nation they have a mandate to serve. The priority health concerns are to be identified jointly by governments, health care organizations, health professionals and the public."[1] This implies medical schools must make explicit contributions to improving health and demonstrate that their "products" - graduates, research findings, and service models - have tangible positive effects on health status in local communities. For instance, a commitment to improve health equity must be evidenced by measures such as selecting students from minority groups and adopting learning strategies with equity issues at their core. But this is not enough. Such a commitment also requires identifying job opportunities where graduates can effectively contribute to reducing health disparities in their practice.

Over the years, the WHO and other organizations have advocated that doctors consciously adopt new roles to become more active in health development, particularly through primary health care. They have insisted on the need for new physicians to acquire new competencies - as communicators and community health leaders, prepared to work in health teams. Some medical associations have voiced support for such an orientation. However, too few medical schools have acted to recast their educational programs accordingly. As a result, a mismatch has persisted between what is being taught and learned in medical schools and what is expected from future doctors in their health systems.

At the same time, health systems themselves often need reform to properly fulfill their social mandate, particularly when it comes to reducing health disparities. Otherwise, they do not offer an optimal working environment for new graduates whose educational programs were designed for this purpose. Graduates may indeed be trained comprehensively as health leaders but end up employed as traditional medical workers. Medical schools must defend efficient employment of their graduates and contribute to reducing inconsistencies between education and practice through collaborative work towards health system transformation.

Until recently, the prevailing assumption was that community orientation and posting, along with problem-based learning, were adequate for medical schools to serve social needs. But now, this notion of social accountability has emerged, meriting attention worldwide, even within traditional medical circles. This concept urges medical schools to go beyond pedagogical innovations and search for optimal integration of their graduates into health systems.

Medical schools...
must have tangible positive
effects on health status

What major initiatives should a medical school take to be recognized as "socially accountable"? In my view, there are at least three. First, the school must provide ample and appropriate learning opportunities for medical students to grasp the complexity of socio-economic determinants in health. It must explicitly adopt a preferential model of practice that integrates the biomedical aspects of diseases into a holistic approach to health and well being, and it must offer role models to reinforce this approach. Second, the school must share responsibility for ensuring equitable and quality health services delivery to an entire population within a well-defined geographical area. In this context, public health and health service research should be declared priority investments to experiment and develop best health practices for involving future graduates.

Third, the school must recognize social accountability as a mark of academic excellence, promoting relevant evaluation and accreditation standards and mechanisms. New standards should be adopted highlighting the school's capacity to anticipate the profile, mix, and number of health professionals needed to meet society's present and future priority health concerns, and its ability to help create relevant work environments for its graduates. Moreover, the school's performance should be assessed by a group composed partly by academic staff and partly by representatives of the society the school intends to serve.

Meeting requirements of social accountability is a real challenge for medical schools - as it is for the health professions, health service organizations, health insurance schemes, and health policy leaders. It is reassuring to see some countries, such as Canada, where national health authorities have officially recommended medical schools adopt a vision of social accountability as central to their strategic development. Several international networks have prioritized these social accountability of health professions schools, including the Network Towards Unity for Health, which set up a task force on social accountability and institutional accreditation (www.the-networktufh.org).

And it is especially encouraging to see the pioneering work of a small but growing number of schools that are transforming their role to become active players in the development of healthier, more equitable societies. The world urgently needs such committed builders of new paradigms in medical education. -1 -

\footnotetext{
1. Boelen C, Heck JE. Defining and measuring the social accountability of medical schools. Geneva: World Health Organization; 1995. WHO document WHO/ $\mathrm{HRH} / 95.7$.
} 